Saudi Journal of Biomedical Research

Abbreviated Key Title: Saudi J Biomed Res ISSN 2518-3214 (Print) |ISSN 2518-3222 (Online)

\title{
Assess the Knowledge, Attitude, and Practices about Biomedical Waste Management among Healthcare Personnel
}

\author{
Dr. Tamilselvi ${ }^{{ }^{*}}$, Ms. Devanithya ${ }^{2}$ \\ ${ }^{1}$ Assistant professor, Department of Community Health Nursing, Saveetha College of Nursing, SIMATS, Chennai, India \\ ${ }^{2}$ P.B.B.sc (Nursing) II year, Saveetha College of Nursing, SIMATS, Chennai, India
}

DOI: $10.36348 /$ sjbr.2020.v05i03.004

| Received: 27.02.2020 | Accepted: 05.03.2020 | Published: 16.03.2020

*Corresponding author: Dr. Tamilselvi

\section{Abstract}

Background: The waste produced in the course of healthcare activities carries a higher potential for infection and injury than any other type of waste. Inadequate and inappropriate knowledge of handling of healthcare waste may have serious health consequences and a significant impact on the environment as well. Objective: The objective was to assess knowledge, attitude, and practices of doctors, nurses, laboratory technicians, and sanitary staff regarding biomedical waste management. Setting: The study was conducted among hospitals (bed capacity >1000) of Allahabad city. Participants: Medical personnel included were, nurses (15) and sanitary staff (15) conclusion: The importance of training regarding biomedical waste management needs emphasis; lack of proper and complete knowledge about biomedical waste management impacts practices of appropriate waste disposal.

Keywords: Biomedical waste management; hospital; medical professional.

Copyright @ 2020: This is an open-access article distributed under the terms of the Creative Commons Attribution license which permits unrestricted use, distribution, and reproduction in any medium for non-commercial use (NonCommercial, or CC-BY-NC) provided the original author and source are credited.

\section{INTRODUCTION}

Health care waste is a unique category of waste by the quality of its composition, source of generation, its hazardous nature and the need for appropriate protection during handling, treatment and disposal. Mismanagement of the waste affects not only the generators, operators but also the common people too.

Bio-medical waste' (BMW) means any solid and/or liquid waste including its container and any intermediate product, which is generated during the diagnosis, treatment or immunization of human beings or animals or in research pertaining thereto or in the production or testing thereof.

Due to the increase in the procedures that are carried out at the various health care setups, excessive amounts of waste have been generated at the centers of care.

Adequate knowledge amongst the health care employees about the biomedical waste management rules and regulations, and their understanding of segregation, will help in the competent disposal of the waste in their respective organizations.
Acceptable management of biomedical waste management begins from the initial stage of generation of waste, segregation at the source, storage at the site, disinfection, and transfer to the terminal disposal site plays a critical role in the disposal of waste. Hence adequate knowledge, attitudes and practices of the staff of the health care institutes play a very important role.

Teaching institutes play a critical role in the health care setup as it is from these places that the future health care professionals and all those persons involved in the care giving to the community are trained.

\section{MATERIALS AND METHODS}

The tool used for the study was a pre-tested, semi-structured closed ended questionnaire which encompassed 30 questions on Knowledge, Attitudes and Practices. The questions on knowledge appraised the participant's knowledge on attributes related to the colour coding and their implications, identification of biomedical hazard symbol, waste categories, and hospital policies for biomedical waste management. The questions on attitude were related to matters like, was biomedical waste hazardous, its management additional burden on their work or if their appropriate management burden on the finances of the hospital, and 
also on legislative measures for waste management. The questions on practice appraised if the study respondents had received any training on biomedical waste management, if they were immunized against hepatitis B and if disinfection of sharps were carried out at the point of generation. The participants filled up the self-administered questionnaires without scope for undue help. The questionnaire was adapted from English to local language by an experienced professional who is involved in translating of health survey questionnaires to accommodate the housekeeping staff. The questionnaire was also back translated to English for checking of possible discrepancies and incorporating if any changes were required. The identity of the study respondents were maintained anonymous at various stages of the study.

\section{Sample Size}

Expecting that $50 \%$ of the study population had precise knowledge (considering the outcome variable) about the rules and legislation of biomedical waste management, with an allowable error of $10 \%$, at $95 \%$ confidence interval.

\section{Sampling Strategy}

The study population was classified according to the different strata based on their designation as interns, staff nurses, and house-keeping staff.

\begin{tabular}{|l|l|}
\hline Strata & Participants \\
\hline Interns & 10 \\
\hline Staff Nurses & 10 \\
\hline House Keeping Staff & 10 \\
\hline Total & 30 \\
\hline
\end{tabular}

Health care workers with a response rate of $43 \%$.

\section{DISCUSSION}

To assess the awareness on biomedical waste segregation among the healthcare workers, an audit was conducted in September 2009. The results revealed, among the samples audited, 53\% were aware of the segregation of cytotoxic drugs, $90 \%$ on segregation and disposal of sharps, $72 \%$ on infectious plastics. Only $67 \%$ were aware of the different colour bags used for segregation. In comparison to a study conducted at Mahatma Gandhi Dental College Hospital Pondicherry, the knowledge about colour coding of biomedical wastes was $74 \%$.
The subsequent audit to assess the practice revealed similar results with the infectious non-plastics segregation 69\%, infectious plastics and PPEs segregation $77 \%$, non-infectious waste segregation $86 \%$ sharps segregation $86 \%$ and cytotoxic wastes $88 \%$. These audits showed the need to improve awareness among HCW's and the necessity to develop new strategies achieves good compliance to waste segregation. The initiatives taken are listed below

\section{CONCLUSION}

Present study reveals that periodic focused training and emphasis on implementation of the policies laid down for bio-medical waste segregation for all $\mathrm{HCW}$ is essential to optimise the compliance to effective segregation strict supervision, daily surveillance, frequent audits and inspections are recommended to implement the bio-medical waste management rules in the hospital. Involvement of the hospital administrators and regular appraisal with the status of bio-medical waste management in waste management and quality steering committee play a pivotal role in executin

\section{REFERENCES}

1. Shukla, S.R. (2002). Manual of Municipal Solid waste, New Delhi, Ministry of urban development May. 2000, Ch. 7: 117. Available from: netlibrary, http://urbanindia.nic.in/publicinfo/swm/ chap7.pdf [Last accessed on 2013 Nov 11].

2. Waste from healthcare activities, Fact Sheet. [Internet] November 2011. Available from: http://www.who.int/mediacentre/factsheets/fs 253/en/ [Last accessed on 2013 Nov 11].

3. Joshi, S.K.(2009). Quality Management in Hospitals. Ch. 43. Bio-medical waste management program. New Delhi: Jaypee Publications.

4. Hospital Waste Management in the Union Territory of Pondichery-An Exploration. Principal Investigator-Dr. Joe Joseph, Co-investigator-Dr. C. G. Ajith Krishnan. 2003-04]. Available from: http://www.pon.nic.in/citizen/science/ppccnew/Joe [Last accessed on 2013 Nov 11].

5. Mohapatra, A., Gupta, M., Shivalli, S., Mishra, C.P., Mohapatra, S.C. (2012). Biomedical waste management practices of doctors: An online snapshot. Natl J Community Med, 3:227-31. 